\title{
Inclusion of marginalised groups in social assistance in crises
}

\author{
Brigitte Rohwerder
}

\author{
February 2022
}

\section{Theme summary}

Leave no one behind is the central, transformative promise of the Sustainable Development Goals (SDGs), aimed at reaching the poorest and combating discrimination and (multiple and intersecting) inequalities that undermine people's human rights. The importance of leaving no one behind is vital in contexts of recurrent shocks, climate and humanitarian crises, protracted conflict, and forced displacement that cause disruption, deprivation, and a lack of access to basic needs. Crises often exacerbate existing inequalities and vulnerabilities for socially excluded and marginalised people, including women and girls, children and youth, older people, people with disabilities, ethnic and religious minorities, and sexual and gender minorities.
Social assistance, in the form of government provided or humanitarian assistance, seeks to alleviate crisis impacts. The structures, systems, and barriers that exclude some people generally can also exclude them from social assistance in crises. Such exclusion, both before and during a crisis, can increase deprivation, reduce resilience to shocks, and exacerbate protection risks by increasing people's vulnerability to exploitation and abuse. Crises, consequently, can disproportionately impact marginalised people. A lack of inclusive social assistance programming thus undermines rights, ethics, and effectiveness in crises - as explored in this summary briefing of the three BASIC Research working papers on inclusion.

A full list of the references cited in this brief can be found at the BASIC Research Zotero library.

\section{Implemented by}

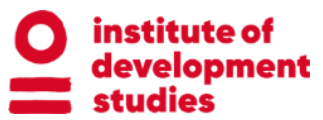

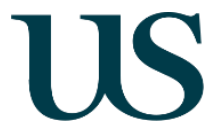

UNIVERSITY OF SUSSEX
UNIVERSITY OF WOLVERHAMPTON

\section{CIDT}

Better Assistance in Crises (BASIC) Research (funded by UKAid) aims to inform policy and programming on how to help poor and vulnerable people cope better with crises and meet their basic needs through more effective social assistance. All costs related to BASIC Research are covered by the UK Foreign, Commonwealth and Development Office. 


\section{State of the evidence and debate}

A review of the evidence indicates that the inclusion of marginalised people in social assistance remains an under-prioritised or emerging area of work in crisis contexts, and within the humanitarian and social protection sectors that provide social assistance in these contexts.

- Context is important: it needs to be considered because the dynamics of inclusion and exclusion are complex, varied across time and space, and require more than technical solutions.

- Approaches to inclusion are not consistent across the humanitarian and social protection sectors and among the actors within them.

- Inclusive approaches often reflect the institutions and people within them that make decisions about social protection or humanitarian response.

- Both sectors have made efforts to include groups of people who are marginalised and vulnerable. Yet these efforts are struggling to capture and accommodate people's intersecting inequalities and vulnerabilities.

- Humanitarian and social protection actors/sectors both take a deeply sceptical view (supported by varying levels of evidence) of the extent to which national governments can and do meet the needs of vulnerable and excluded groups.

The under-prioritisation of inclusion means that the experiences of marginalised people in crises are also under-explored - specifically their experiences related to the risks faced when navigating access to social assistance, and the positive and negative outcomes of receiving or not receiving assistance.

\section{Table 1: What do we know about the main outcomes and risks of accessing social assistance?}

\begin{tabular}{|c|c|c|}
\hline $\begin{array}{l}\text { Outcomes of not receiving social } \\
\text { assistance }\end{array}$ & $\begin{array}{l}\text { Outcomes of receiving social } \\
\text { assistance }\end{array}$ & $\begin{array}{l}\text { Possible risks in accessing social } \\
\text { assistance }\end{array}$ \\
\hline $\begin{array}{l}\text { Lack of access to social assistance in } \\
\text { crises for women and girls, children and } \\
\text { youth, older people, people with } \\
\text { disabilities, ethnic and religious } \\
\text { minorities, and sexual and gender } \\
\text { minorities, increases the inequalities they } \\
\text { face; deepens poverty; causes } \\
\text { household tensions and negative coping } \\
\text { mechanisms; and leaves these people } \\
\text { vulnerable to (sexual) exploitation and } \\
\text { abuse. } \\
\text { However, for some with stigmatised } \\
\text { identities, not accessing programmes } \\
\text { can help them to manage their safety by } \\
\text { remaining invisible. }\end{array}$ & $\begin{array}{l}\text { Depending on how it is delivered, social } \\
\text { assistance can help improve food } \\
\text { security and nutrition; reduce economic } \\
\text { vulnerability and help households meet } \\
\text { their basic needs; reduce stress and } \\
\text { household tensions; give people a sense } \\
\text { of autonomy, confidence, and respect; } \\
\text { reduce negative coping mechanisms; } \\
\text { reduce gender-based violence; improve } \\
\text { health, education, and wellbeing; and } \\
\text { improve community relations. } \\
\text { However, accessing social assistance } \\
\text { can also expose people to violence and } \\
\text { risk. This can result in stigma, shame, } \\
\text { and increased mental health problems. It } \\
\text { may also cause community tensions and } \\
\text { disrupt people's usual social support } \\
\text { mechanisms. }\end{array}$ & $\begin{array}{l}\text { The risks faced when accessing social } \\
\text { assistance, some of which also apply to } \\
\text { those who are excluded from social } \\
\text { assistance, and which are balanced by } \\
\text { some of the positive outcomes, include: } \\
\text { neglect and lack of understanding in } \\
\text { social assistance programming; } \\
\text { corruption and discrimination; lack of } \\
\text { information about social assistance } \\
\text { programming; problems with system } \\
\text { bureaucracy; accessibility issues; sexual } \\
\text { exploitation and abuse from programme } \\
\text { providers and others in the community; } \\
\text { increased community tensions; } \\
\text { increased household tensions and } \\
\text { gender-based violence; stigma; theft; } \\
\text { and insufficient assistance that leaves } \\
\text { people at continued risk of exploitation } \\
\text { and abuse. }\end{array}$ \\
\hline
\end{tabular}

Note: Most of the evidence comes from papers looking at the experiences of women and girls, with limited research into the experiences of other marginalised groups of social assistance in crises. 


\section{Gaps in the evidence}

Evidence is emerging around the inclusion or exclusion of marginalised people, especially women and girls, in social assistance in crises, and about their experiences, the risks they may encounter when accessing it, and the positive, and sometimes negative, outcomes they experience. Such emerging evidence indicates the importance of ensuring the inclusion of marginalised and 'left-behind' people in social assistance in crises. However, much is still unknown about this under-explored area. Basic measures, such as data disaggregation, are not routinely undertaken, making it harder to understand different groups' experiences of social assistance. Key gaps in understanding need to be addressed in order to move towards safer, dignified, inclusive, and (consequently) more effective social assistance in crisis contexts.

\section{Table 2: The knowledge gaps in relation to the inclusion of marginalised people in social assistance in crises}

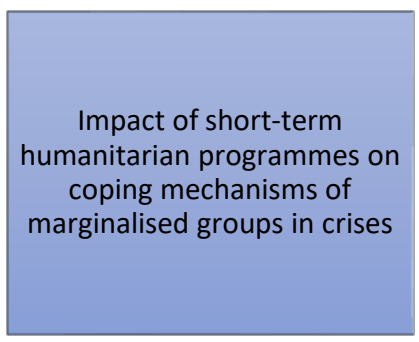

Comparing programming that directly addresses drivers of exclusion, with programmes meeting practical, immediate consumption needs, in terms of difference made to the inclusion of marginalised people
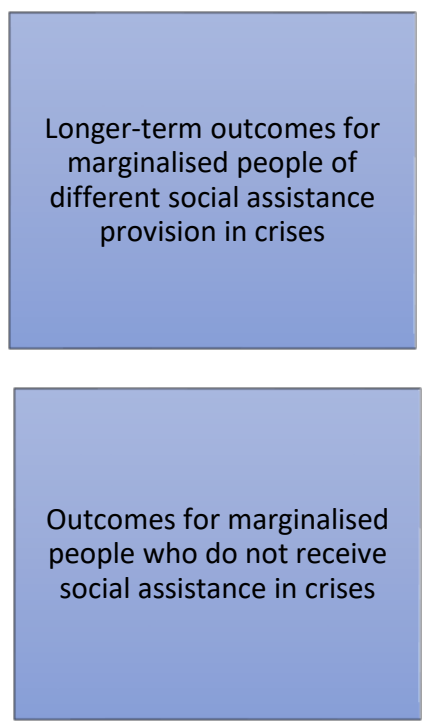

Experiences of youth, older people, people with disabilities, ethnic and religious minorities, and sexual and gender minorities of the risks and outcomes of accessing social assistance in crises
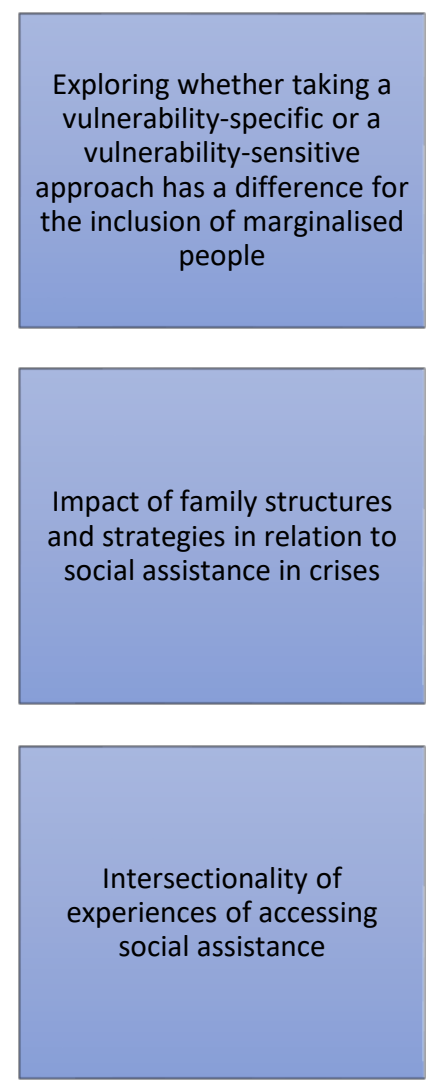

The different risks and outcomes for marginalised people in different crisis contexts, and the interactions between these, when navigating government and non-government provided social assistance

Experiences of social assistance (as opposed to the wider social protection sector) and cash-based transfers (as opposed to a wider set of humanitarian instruments)

Gender is often only focused on women and girls and neglects the experiences of men and boys of accessing social assistance in crises

The ways in which risks when accessing social assistance can be mitigated for marginalised people
Comparing links to complementary programmes on livelihoods and climate resilience with links to those on health and protection, in terms of the difference they make to the inclusion of marginalised people

Exploring the difference that non-discriminatory approaches have, compared to equitable approaches, for the inclusion of marginalised people

Whether positive outcomes for marginalised people observed in stable settings are replicated in crisis settings

Differences in experiences of accessing social assistance, depending on the type of social assistance provided (cash, vouchers, food and non-food items, public works programmes, fee waivers, and subsidies) 


\section{Directions for research}

A greater understanding is required of the processes of social exclusion/inclusion in social assistance in different crisis contexts and the needs of different marginalised people, who often experience intersecting inequalities. This would ensure that their experiences of social assistance in crises are positive and beneficial. As a result, the next steps for research in this area include:

- Exploring marginalised people's lived experiences when navigating access to social assistance in crises and the risks, threats, barriers, and differences relating to accessing government and humanitarian provided social assistance in crises. And consequently, how and in what circumstances social assistance in crises can be more responsive to and inclusive of marginalised people's experiences and perceptions of what enables and constrains safe, dignified, and inclusive protection and support, including how this may vary depending on the context.

- Exploring the outcomes for marginalised and vulnerable groups of people of the different decisions made by social protection and humanitarian actors in relation to their approach to inclusion - whether this is vulnerability-specific or -sensitive, relief or transformative, practical or strategic, holistic or vulnerable-group targeted.

- Exploring what local-level organisations and staff that deliver social protection and humanitarian assistance do on the ground; and what values, norms, and capacities exist at the local organisational and individual staff level that enable or undermine inclusive approaches to social assistance in crises.

This thematic brief is a shortened version of three BASIC Research Working Papers. To explore this research theme in more detail please refer to the BASIC Research Working Papers:

\section{Oosterhoff, P. and Yunus, R.M. (2022) The Effects of Social Assistance Interventions on Gender, Familial, and Household Relations Among Refugees and Displaced Populations: A Review of the Literature on Interventions in Syria, Iraq, Jordan, and Lebanon, BASIC Research Working Paper 11, Brighton: Institute of Development Studies, DOI: 10.19088/BASIC.2022.011}

Rohweder, B. and Szyp, C. (2022) The Risks and Outcomes of Getting Help for Marginalised People: Navigating Access to Social Assistance in Crises, BASIC Research Working Paper 7, Brighton: Institute of Development Studies, DOI: 10.19088/BASIC.2022.007

Slater, R. (2022) Humanitarian and Social Protection Approaches to Inclusion: Knowledge Gaps and Implications for Working in the Humanitarian-Social Protection Nexus, BASIC Research Working Paper 16, Brighton: Institute of Development Studies, DOI: 10.19088/BASIC.2022.016

\section{Acknowledgements and Disclaimer}

This document was developed by the Better Assistance in Crises (BASIC) Research programme. BASIC is implemented by the Institute of Development Studies (IDS), the University of Sussex and the Centre for International Development and Training, funded by UKAid from the UK government. The views expressed in this document are entirely those of the authors and do not necessarily represent views or policies of the UK governments official policies.

(C) IDS copyright 2022. Copyright in the typographical arrangement and design rests with IDS.

This publication (excluding the logos) may be reproduced free of charge in any format or medium, provided that it is reproduced accurately and not used in a misleading context. The material must be acknowledged as IDS copyright with the title and source of the publication specified.

Published by IDS.

DOI: $\underline{10.19088 / B A S I C .2022 .023}$ 